\title{
Humboldt und die Natur
}

\section{Erhard Taverna}

Dr. med., Mitglied der Redaktion

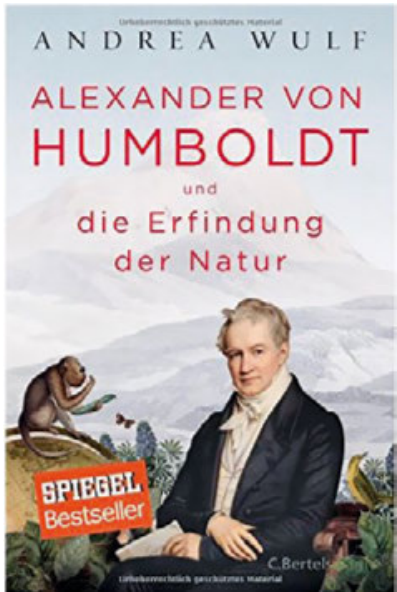

Andrea Wulf

Alexander von Humboldt und die Erfindung der Natur

München: C. Bertelsmann Verlag, 2015. 560 Seiten, $27.90 \mathrm{CHF}$

ISBN: 978-3-570-10206-0

Alexander von Humboldt, Entdeckungsreisender und Naturforscher, wurde 1769 als Sohn einer preussischen Adelsfamilie geboren und starb 1859 in Berlin. Sein hundertster Geburtstag wurde weltweit gefeiert. Moskau bezeichnete ihn als «Shakespeare der Wissenschaften", in New York verschwanden die Häuser hinter riesigen Plakaten, die sein Gesicht zeigten. Boston sah in ihm ein "Weltwunder", die Daily News in London schrieb, er sei eng mit dem Universum verbunden, und König Wilhelm IV. meinte, er sei der grösste Mann seit der Sintflut. Ein Meeresstrom, Berghöhen, Gletscher,

\section{Seine Naturbeschreibungen schufen die Grund- lagen für das Verständnis einer vernetzten Umwelt.}

Flüsse, Naturparks, Wasserfälle, Pflanzen, Tiere, Mineralien und viele Schulen tragen seinen Namen. Aus Nevada wäre beinahe der Staat Humboldt geworden, auf dem Mond gibt es ein Mare Humboldtianum.

\section{Begründer der Pflanzengeographie}

Seine Reisen durch Süd- und Mittelamerika sowie Zentralasien machten den Begründer der Pflanzengeographie weltbekannt. Er war ein sprachbegabter Weltbürger, Geograph, Meteorologe, Botaniker, Geologe und Anthropologe, ein globaler Netzwerker mit einem gigantischen Briefwechsel und einer unstillbaren Neugier. Seine zahlreichen Schriften verbanden exakte Messungen und Beobachtungen mit einer grossen schriftstellerischen Begabung. Mehrbändige Bücher wie sein Kosmos waren Bestseller, die, in zehn Sprachen übersetzt, mehrere Generationen von Forschern wie Charles Lyell, Charles Darwin, oder Ernst Haeckel massiv beeinflussten. Seine Naturbeschreibungen schufen die Grundlagen für das Verständnis einer vernetzten Umwelt. Er korrespondierte mit zahlreichen

\section{Goethe lehrte ihn, Natur und Kunst, Fakten und Fantasie zu verbinden.}

Politikern, mit Simón Bolívar und Thomas Jefferson, er geisselte die Zustände in den spanischen Kolonien und verurteilte aus eigener Anschauung vehement die Sklaverei, den Rassendünkel und den Raubbau an der Natur. Goethe war von ihm begeistert, ebenso Henry David Thoreau, bis heute einer der meistgelesenen und populärsten amerikanischen Schriftsteller. John Muir, ein geistiger Schüler Humboldts und Vorkämpfer des Umweltschutzes in den USA, hat den Präsidenten Theodore Roosevelt stark beeinflusst und damit viel zum Entstehen des Yosemite Valley Nationalparks beigetragen.

\section{In Vergessenheit geraten}

Einst ein Superstar, Liebling aller gebildeten Stände in Paris, London und Berlin, geriet Alexander von Humboldt als Person weitgehend in Vergessenheit. Bis Daniel Kehlmanns Roman Die Vermessung der Welt die beiden Genies Humboldt und Gauss wieder zurück ins Bewusstsein einer weltweiten Leserschaft beförderte. 2012 hat ein kontrovers diskutierter Spielfilm den Bekanntheitsgrad noch gesteigert. Dem raffinierten Spiel mit Fiktionen und Fakten folgt zehn Jahre später die mehrfach preisgekrönte Biographie von 
Andrea Wulf Alexander von Humboldt und die Erfindung der Natur. Zuerst der philosophische Abenteuerroman eines Schriftstellers, dann die gründlich recherchierte Erkundung einer in Deutschland aufgewachsenen und heute in England lebenden Historikerin. Andrea Wulf betont das Humboldtsche Naturverständnis, das sie als wegweisend für die Lösung ökologischer Probleme darstellt. Goethe lehrte ihn, Natur und Kunst, Fakten und Fantasie zu verbinden. «Die Natur muss gefühlt werden», schrieb er an Goethe. Die Aussenwelt, urteilte der reisende Forscher, beeinflusst von Kants Philosophie, existiere nur insoweit, als wir sie in uns aufnähmen. Diese sei in unserem Verstand vorgeformt und forme wiederum unser Verständnis der Natur. Schelling, Hauptvertreter des deutschen Idealismus, hat das so formuliert: «Die Natur schlägt im Menschen ihre Augen auf und merkt,

\section{Einst ein Superstar, Liebling aller gebildeten Stände in Paris, London und Berlin, geriet Alexander von Humboldt als Person weitgehend in Vergessenheit}

dass sie da ist.» Eine Prise Naturphilosophie würde unserem Wissenschaftsbetrieb gut tun, denn die ausschliesslich objektivierende Naturbetrachtung macht uns selber zu Objekten. Mit vielem, was die Enzyklika Laudato si' von Papst Franziskus 2015 auflistet, wäre Humboldt sicher einverstanden gewesen: Gerechtig- keit in Umweltdiskussionen heisse, die Klagen der Armen ebenso zu hören wie die Klage der Erde; und alles sei miteinander verbunden, die innige Verbundenheit

\section{Er blieb zeitlebens ein getriebener und,} bei allem Starkult, ein einsamer Mann.

mit den anderen Wesen in der Natur mit Zärtlichkeit und Mitleid und Sorge um die Menschen; und jegliche Grausamkeit gegenüber irgendeinem Geschöpf widerspreche der Würde des Menschen.

\section{Zeitlebens ein Getriebener}

Humboldts Leben hatte auch viele tragische Seiten. Er blieb zeitlebens ein getriebener und, bei allem Starkult, ein einsamer Mann. Er erlebte die napoleonischen Koalitionskriege, sah Revolutionen in Südamerika und Europa scheitern und musste aus Geldgründen einem reaktionären preussischen König als Kammerherr Gesellschaft leisten. Den imperialen Machtwahn seiner Zeit konnte er nicht verhindern. Viel lieber wäre er in Paris geblieben, als in seiner vollgestopften Wohnung in der Oranienburgerstrasse in einem Berlin, das er wegen der täglichen Militäraufmärsche verachtete.

\footnotetext{
Literatur

Kehlmann D. Die Vermessung der Welt, rowohlt, 1. Auflage, September 2005.
} 